\title{
Acoustic Emission Study of the Deformation Behavior of Mg-Mn Alloys Containing Rare Earth Elements
}

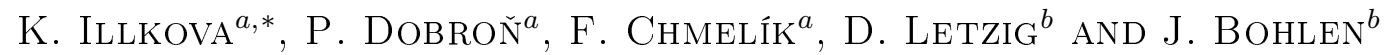 \\ ${ }^{a}$ Department of Physics of Materials, Charles University Prague, Ke Karlovu 5, 12116, Prague 2, Czech Republic \\ ${ }^{b}$ Helmholtz-Zentrum Geesthacht, Zentrum für Material- und Küstenforschung GmbH \\ Max-Planck-Str. 1, D21502 Geesthacht, Germany
}

\begin{abstract}
Magnesium-manganese ( $\mathrm{Mg}-\mathrm{Mn})$ based alloys with various chemical composition were processed by indirect extrusion at two different speeds. Alloying with $\mathrm{Mn}$ and rare earth elements has significant influence on the microstructure and on the texture of the alloys under investigation. This paper deals with the acoustic emission analysis of the deformation behavior of the extruded $\mathrm{Mg}-\mathrm{Mn}$ alloys. The acoustic emission measurements were performed during the uniaxial tension and compression tests, and the obtained results are discussed with respect to the influence of rare-earth elements on the deformation behavior, particularly in terms of the activation of dislocation glide and twinning.
\end{abstract}

PACS: 81.05.Bx, 81.20.Hy, 83.50.Uv, 81.40.Ef, 83.50.-v, 43.40.Le

\section{Introduction}

A major impediment to the wide use of $\mathrm{Mg}$ alloys is their poor workability at room temperature (RT). This is connected with a limited number of slip systems available for deformation at RT. Basal slip and twinning can be easily activated at RT, because of their low critical resolved shear stress (CRSS). From a recent work [1], it is known that the prismatic $\langle a\rangle$ slip systems can also be activated at RT. However, two independent basal slip systems and two prismatic systems are still not sufficient to fulfil the von Mises criterion for homogeneous deformation without crack formation. Consequently, twinning becomes important during deformation at RT.

Alloying elements, such as Li, Ca, Y, La, Ce, Nd, Sm and $\mathrm{Gd}$ can change the $c / a$ ratio [2] of $\mathrm{Mg}$ and reduce the CRSS for non-basal slip. The solubility of $\mathrm{Ce}$ in $\mathrm{Mg}$ at $400^{\circ} \mathrm{C}$, which was reached during the extrusion process, is about 0.08 wt $\%$ [3]. The Ce addition is known to produce second-phase particles in $\mathrm{Mg}$ [4], which can be utilized to affect the recrystallization texture and the grain size. It has been reported that the addition of $\mathrm{Ce}$ to $\mathrm{Mg}-\mathrm{Mn}$ alloy [5] reduces the $c / a$ ratio only slightly $(<0.001)$. However, this small reduction of the $c / a$ ratio is not sufficient to affect the activation of non-basal slip systems [6]. Furthermore, texture modelling and transmission electron microscopy (TEM) studies indicate that the addition of $\mathrm{Y}$ facilitates the glide of $\langle c+a\rangle$ dislocations in pyramidal planes of $\mathrm{Mg}$ (the role of $\mathrm{Y}$ was attributed to the stability of $\langle c+a\rangle$ partial dislocations [7]). The addition of Nd to Mg is known to improve the solid-solution strengthening, also at elevated temperatures, and to increase the corrosion resistance [8].

The rare-earth (RE) additions have a distinct influence on the texture, i.e. the texture strength as well as the ori-

* corresponding author; e-mail: parfenenko@karlov.mff.cuni.cz entation distribution [9-11]. Microalloying with RE elements also decreases the grain size of the $\mathrm{Mg}-\mathrm{Mn}$-based alloys [11, 12], which is known to have a significant influence on the mechanical behaviour $[13,14]$. An efficient way to modify the deformation behaviour, and in particular the activity of twins, is to alter the texture. The typical extrusion texture of $\mathrm{Mg}$ alloys stems from grains oriented unfavourable for the basal slip, if the alloy is deformed in the extrusion direction. If the texture is weak, the orientation distribution of the respective slip planes is wide and there are many grains favourably aligned for the basal slip. Thus a weak texture can lead to improved formability. However, weakening of the texture also leads to a decrease of the yield stress [15].

The objective of this work is an acoustic emission (AE) study on the influence of RE elements (Ce, Y, Nd) on the tension and compression deformation behaviour of $\mathrm{Mg}-\mathrm{Mn}$-based alloys fabricated by indirect extrusion at two different extrusion speeds. The relation between the microstructure and the mechanical behaviour of the extruded alloys will be also discussed.

\section{Experimental procedure}

The alloys were based on the commercial $\mathrm{Mg}$ alloy M1 (Mg-1wt\%Mn), alloyed with RE elements cerium (Ce), yttrium $(\mathrm{Y})$ and neodymium $(\mathrm{Nd})$, and are denoted as ME11 (Mg-1wt\%Mn-1wt\%Ce), MW11 (Mg-1wt\%Mn1wt\%Y), MN11 (Mg-1wt\%Mn-1wt\%Nd), respectively. Details on the alloy preparation are presented in [11]. All billets were indirectly extruded at $300^{\circ} \mathrm{C}$ with an extrusion ratio of 1:30 to round bars with final diameter of $17 \mathrm{~mm}$. The extrusion speeds were 1 and $10 \mathrm{~m} / \mathrm{min}$. For simplicity, these extrusion rates will be referred to as the "slow" and the "fast" extrusion, respectively [16, 17].

After being extruded, the specimens were sectioned along the extrusion axis and the microstructure was examined by light microscopy. Standard metallographic sample preparation techniques were employed, including 
the use of an etchant based upon picric acid [18]. The average and median grain sizes were determined from several micrographs of longitudinal sections using a computer aided linear intercept measurement.

Uniaxial tension and compression deformation tests were performed with a universal testing machine Zwick ${ }^{\circledR} \mathrm{Z} 50$ at a constant strain rate of $10^{-3} \mathrm{~s}^{-1}$ at RT. The samples for tensile tests had a diameter of $6 \mathrm{~mm}$ and a gauge length of $60 \mathrm{~mm}$. The samples for compression tests had a diameter of $11 \mathrm{~mm}$ and a length of $16.5 \mathrm{~mm}$.

A DAKEL-XEDO-3 computer controlled AE system with a miniaturized MST8S piezoelectric transducer was used to record AE on the basis of the two-threshold-level detection [19] enabling simple amplitude discrimination at proper settings. The transducer was attached to the specimen surface with the help of silicon grease and a spring. The AE signal sampling rate was $4 \mathrm{MHz}$, the threshold voltage for the total AE count $\mathrm{d} N_{\mathrm{C} 1} / \mathrm{d} t$ was $725 \mathrm{mV}$ and for the burst $\mathrm{AE}$ count $\mathrm{d} N_{\mathrm{C} 2} / \mathrm{d} t$ was $1440 \mathrm{mV}$. The transducer provides almost point AE detection (diameter $3 \mathrm{~mm}$ ), and has a flat response in a frequency band from 100 to $600 \mathrm{kHz}$ and a sensitivity of $55 \mathrm{~dB}$ ref. $1 \mathrm{~V}_{\text {ef }}$.

\section{Experimental results}

The grain structure of the extruded profiles is characterized in Table I. Generally, after slow extrusion, the microstructure is partly recrystallized and consists of large, elongated, unrecrystallized "grains" surrounded by newly formed, smaller recrystallized grains. The degree of recrystallization increases with the extrusion rate due to the higher temperature achieved during the fast extrusion process [20]. In partly recrystallized microstructure, the presence of a few large grains likely resulted in overestimating the average grain size, therefore no difference in the average grain size of the slowly and the fast extruded ME11 and MW1 was observed (Table I). To characterize the grain size more precisely, the median grain size was also calculated. The median grain size indicates that the fast extruded alloys have larger grains than the slowly extruded ones. The grains were also grouped according to their size: up to $5 \mu \mathrm{m}$ and up to $20 \mu \mathrm{m}$, as shown in Table I. After slow extrusion, all alloys except M1 contain $50-60 \%$ of grains smaller than $5 \mu \mathrm{m}$ and $80-90 \%$ of grains smaller than $20 \mu \mathrm{m}$. After fast extrusion, all RE-containing alloys consist of $90-98 \%$ of grains smaller than $20 \mu \mathrm{m}$.

Grain structure of the extruded alloys.

TABLE I

\begin{tabular}{c|c|c|c|c|c|c}
\hline \hline Alloy & $\begin{array}{c}\text { Extrusion } \\
\text { speed }\end{array}$ & $\begin{array}{c}\text { Average } \\
\text { grain size } \\
{[\mu \mathrm{m}]}\end{array}$ & $\begin{array}{c}\text { Median } \\
\text { grain size } \\
{[\mu \mathrm{m}]}\end{array}$ & $\begin{array}{c}\text { Fraction } \\
\text { of recrystallized } \\
\text { microstructure } \\
{[\%]}\end{array}$ & $\begin{array}{c}\text { Fraction } \\
\text { of grains } \\
\text { up to } 5 \mu \mathrm{m} \\
{[\%]}\end{array}$ & $\begin{array}{c}\text { Fraction } \\
\text { of grains } \\
\text { up to } 20 \mu \mathrm{m} \\
{[\%]}\end{array}$ \\
\hline \multirow{2}{*}{$\mathrm{M} 1$} & $1 \mathrm{~m} / \mathrm{min}$ & 8 & 6 & 0.65 & 54 & 90 \\
& $10 \mathrm{~m} / \mathrm{min}$ & 70 & 55 & 1 & 1.5 & 17 \\
$\mathrm{ME} 11$ & $1 \mathrm{~m} / \mathrm{min}$ & 7 & 3 & 0.6 & 61 & 80 \\
& $10 \mathrm{~m} / \min$ & 7 & 5 & 0.95 & 27 & 98 \\
$\mathrm{MW} 11$ & $1 \mathrm{~m} / \min$ & 11 & 3.5 & 0.58 & 67 & 90 \\
& $10 \mathrm{~m} / \min$ & 10 & 7 & 0.95 & 60 & 92 \\
$\mathrm{MN11}$ & $1 \mathrm{~m} / \min$ & 4 & 4 & 1 & 65 & 92 \\
& $10 \mathrm{~m} / \min$ & 9 & 9 & 0.98 & 39 & 97
\end{tabular}

TABLE II

Mechanical properties measured in straining parallel to the extrusion direction: tensile yield stress (TYS), ultimate tensile stress (UTS), compression yield stress (CYS), ultimate compression stress (UCS), tension-compression asymmetry (CYS/TYS).

\begin{tabular}{c|c|c|c|c|c|c|c|c}
\hline \hline Alloy & $\begin{array}{c}\text { Extrusion } \\
\text { speed }\end{array}$ & $\begin{array}{c}\text { TYS } \\
{[\mathrm{MPa}]}\end{array}$ & $\begin{array}{c}\text { UTS } \\
{[\mathrm{MPa}]}\end{array}$ & $\begin{array}{c}\text { Fracture } \\
\text { strain } \\
{[\%]}\end{array}$ & $\begin{array}{c}\text { CYS } \\
{[\mathrm{MPa}]}\end{array}$ & $\begin{array}{c}\text { UCS } \\
{[\mathrm{MPa}]}\end{array}$ & $\begin{array}{c}\text { Fracture } \\
\text { strain } \\
{[\%]}\end{array}$ & CYS/TYS \\
\hline \multirow{2}{*}{$\mathrm{M} 1$} & $1 \mathrm{~m} / \mathrm{min}$ & 183 & 243 & 5.5 & 126 & 386 & 13.0 & 0.69 \\
& $10 \mathrm{~m} / \mathrm{min}$ & 189 & 261 & 5.3 & 65 & 346 & 13.0 & 0.34 \\
ME11 & $1 \mathrm{~m} / \mathrm{min}$ & 288 & 300 & 14.0 & 181 & 386 & 10.5 & 0.63 \\
& $10 \mathrm{~m} / \min$ & 189 & 251 & 21.5 & 137 & 343 & 13.0 & 0.72 \\
MW11 & $1 \mathrm{~m} / \min$ & 204 & 248 & 21.0 & 156 & 389 & 10.5 & 0.76 \\
& $10 \mathrm{~m} / \min$ & 143 & 221 & 28.5 & 121 & 342 & 16.5 & 0.85 \\
MN11 & $1 \mathrm{~m} / \min$ & 151 & 214 & 34.0 & 159 & 342 & 21.5 & 1.05 \\
& $10 \mathrm{~m} / \min$ & 102 & 196 & 39.0 & 109 & 314 & 21.5 & 1.05
\end{tabular}


The values of the yield stress and the ultimate stress for tension and compression tests are presented in Table II. In all cases except MN11, there is a typical tension-compression asymmetry (CYS/TYS), i.e. large differences between yield stresses in tension tests (TYS) and in compression tests (CYS) occur. The yield stress and also the fracture strain in tension are much higher than those measured in compression. For each alloy, after fast extrusion the TYS and CYS are lower than after slow extrusion. The alloys ME11 and MW11 have higher TYS, CYS, CYS/TYS and the fracture strain by comparison with M1.

The deformation curves from tensile tests are shown in Fig. 1. The curves in Fig. 1 are correlated to the time dependences of the AE count rates at both threshold levels. During the tensile tests of M1 after slow and fast extrusion (Fig. 1a,b), the AE count rates increase to a peak value at the macroscopic yield point and, then, a relatively high $\mathrm{AE}$ response remains during the entire test. In the case of the fast extruded M1 alloy, the AE count rates are distinctly higher than in the case of the slowly extruded alloy. Also the AE response of the M1 alloy is higher than by the other alloys (for both extrusion speeds).

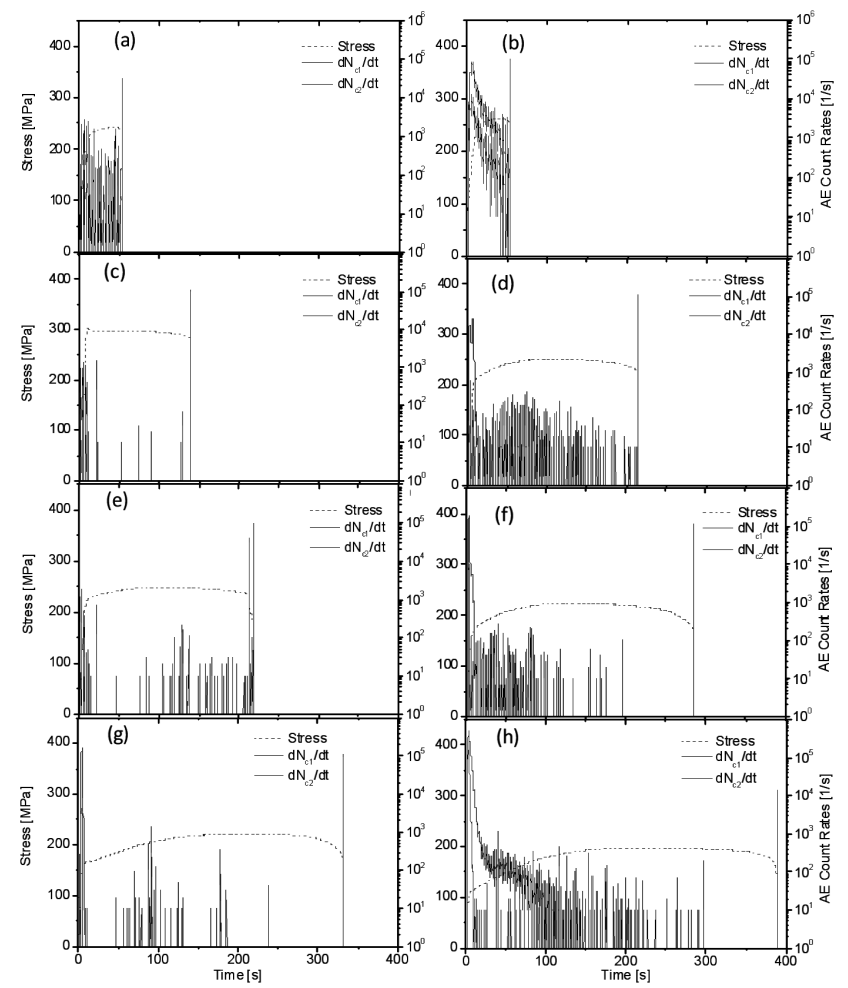

Fig. 1. The deformation curves (broken lines) and the $\mathrm{AE}$ count rates $\mathrm{d} N_{\mathrm{C} 1} / \mathrm{d} t$ (black lines) $\mathrm{d} N_{\mathrm{C} 2} / \mathrm{d} t$ (grey lines) in tension tests. (a) Slowly extruded M1 alloy, (b) fast extruded M1 alloy, (c) slowly extruded ME11 alloy, (d) fast extruded ME11 alloy, (e) slowly extruded MW11 alloy, (f) fast extruded MW11 alloy, (g) slowly extruded MN11 alloy, (h) fast extruded MN11 alloy.
The slowly extruded ME11 alloy (Fig. 1c) exhibits an extremely weak AE activity during the test. Only a brief peak at the yield point is found. In the fast extruded alloy (Fig. 1d), the AE count rates are slightly higher and persist during the whole test (reaching a maximum at the yield point). A very similar result is also found for the alloy MW11 (Figs. 1e,f) fabricated at both extrusion speeds.

The slowly extruded MN11 alloy (Fig. 1g) exhibits also the characteristic AE peak at the yield point only. In the fast extruded alloy the $\mathrm{AE}$ count rates show a distinct peak at the beginning of plastic deformation followed by a subsequent AE activity, which decreases with strain. The higher AE response in the case of the fast extruded MN11 (Fig. 1h) than in the case of the slowly extruded alloy is consistent with the increase of the average grain size from $4 \mu \mathrm{m}$ to $9 \mu \mathrm{m}$.

The AE response during compression tests (Fig. 2) is significantly different from that which was observed during the tension tests (Fig. 1). The count rates $\mathrm{d} N_{\mathrm{C} 2} / \mathrm{d} t$ have almost the same peak values as $\mathrm{d} N_{\mathrm{C} 1} / \mathrm{d} t$. As $\mathrm{d} N_{\mathrm{C} 2} / \mathrm{d} t$ represents signals of the burst type, whereas $\mathrm{d} N_{\mathrm{C} 1} / \mathrm{d} t$ involves all detected signals, it can be concluded that the $\mathrm{AE}$ is dominated by the signals of the burst type. In all compression tests, the AE response almost vanished in further course of plastic deformation (when distinct strain hardening took place).

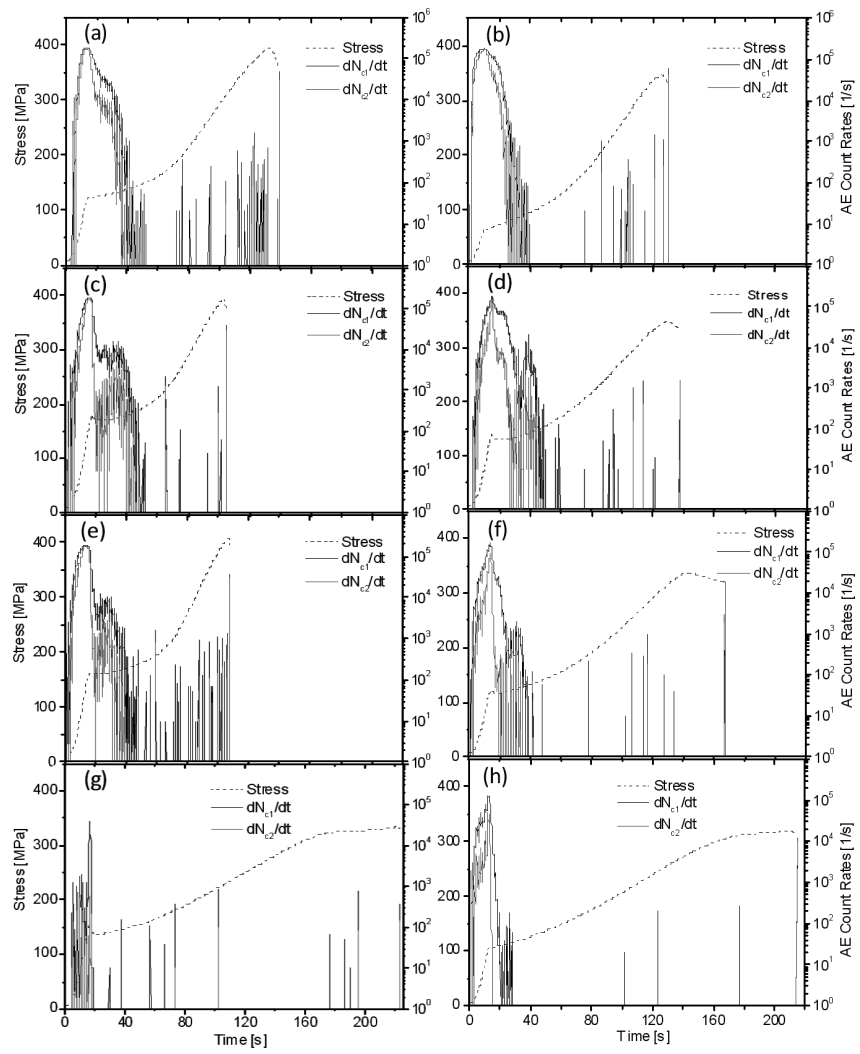

Fig. 2. As in Fig. 1, but in compression tests. 
The results for the M1 alloy at both extrusion speeds are shown in Figs. 2a,b. The AE count rates increase to peak values at the macroscopic yield point. In slowly extruded M1, the peak of the AE activity has a slight step.

In compression tests of ME11 (Fig. 2c,d) and MW11 (Fig. 2e,f), after the slow and the fast extrusions, the first $\mathrm{AE}$ peak at the yield point is followed by a distinct second one. The level of the AE activity is lower in the fast extruded alloys than in those extruded slowly. Fast extruded ME11 exhibits a slightly expressed step on the first peak.

There are no distinct differences in the AE activity as a function of the extrusion rate for MN11, see Fig. 2g,h. The AE activity of this alloy shows a single peak at both extrusion speeds.

\section{Discussion}

The alloys with pronounced textures (M1, ME11, MW11) exhibit a more distinct tension-compression asymmetry than the alloy with weak texture (MN11). This asymmetry arises from the fact that neither basal glide nor pyramidal twinning is easily activated in the $\mathrm{Mg}$ alloys with the fibre texture, if deformed in tension. In compression, twinning can be anticipated as the main deformation mechanism at RT.

The slowly extruded ME11 alloy has the highest TYS and CYS of all alloys. M1 and ME11 after slow extrusion show similar average grain sizes and textures, but they exhibit a significantly different TYS and fracture strain. These differences have to be related to second-phase particles in ME11 [18]. These particles are distributed at the grain boundaries and in the grain interiors and can act as obstacles to dislocation motion. MW11 shows a wider distribution of the basal plane orientation than ME11 [9]. Thus, in MW11 there are more grains preferably oriented for basal slip. This leads to a moderately higher fracture strain and a higher CYS/TYS ratio. The fast extruded MW11 alloy (Fig. 2c) has the same average grain size as the slowly extruded one. Nevertheless, from the median grain sizes it is visible that the recrystallized grains are larger in fast extruded MW11 than in slowly extruded one.

The fast extruded MN11 alloy (Fig. 2d) has the lowest value of the TYS among the alloys in this study, but much more important features of this material are the absence of CYS/TYS yield asymmetry and the highest fracture strain (Table II). Such unique mechanical properties are the result of the different microstructure and the texture if compared with those of all other alloys. Whereas the average grain size of MN11 is comparable with that of other materials, the grain structure is much more homogeneous than in the case of the all other alloys. The superior fracture strain can be explained by the weak texture, which is a result of the homogeneous microstructure. After the slow extrusion, the alloy contains $92 \%$ of grains smaller than $20 \mu \mathrm{m}$, and after fast extrusion this fraction reaches $97 \%$.
The activity of the deformation mechanisms is characterized by the AE response. In all tension tests, a distinct AE peak occurs at the beginning of plastic deformation, which may be explained by the activation of dislocation glide (which is anticipated as the prevailing AE source mechanism in tension).

The level of the AE activity in the M1 alloy after the slow and after the fast extrusion is also related to the grain structure. After the slow extrusion, the M1 alloy contains $54 \%$ of small $(<5 \mu \mathrm{m})$ grains whereas the fast extruded alloy contains only $1.5 \%$ of such grains. However, the slowly extruded material consists of $90 \%$ of grains sized up to $20 \mu \mathrm{m}$, while the fast extruded alloy contains only $17 \%$ of them. It is particularly interesting that in spite of the significant difference in the amounts of very large grains, the $\mathrm{AE}$ activities in the compression tests are similar. Consequently, twinning occurring in large grains (unrecrystallized, favourably oriented grains in the case of the slow extrusion and large recrystallized grains in the case of the fast extrusion) is obviously responsible for the strong AE activity.

The AE activity in tension is fairly comparable for the ME11 and MW11 alloys. In the compression tests of ME11 and MW11 after both extrusion speeds, the AE count rates form two separate peaks, the first one occurring after the yield point and the second one in a strain range where the work hardening rate starts to increase. In our recent work [13] we have shown by repeated compressive tests to respective values of strain, with subsequent electron backscattering diffraction (EBSD) analysis that (10-12)-twins preferentially appear in large grains and only with increasing strain smaller grains also tend to twin. Thus, the first AE peak can be ascribed to twinning in large grains. The second AE peak is then due to twinning in smaller grains [13].

In the slowly extruded M1 alloy, in spite of the bimodal microstructure, two separate AE peaks were not observed and a small step on the AE peak appeared only. This step can be explained by overlapping of two closely localized AE peaks resulting in one slightly elongated peak.

The AE response in MN11 after both extrusion speeds is consistent with its completely homogeneous and fully recrystallized microstructure, i.e. a single AE peak occurs at the yield point and the AE response is higher after the fast extrusion (higher fraction of larger grains).

\section{Summary and conclusions}

The AE activity depends on the grain size and on the texture of the alloys.

The slowly extruded ME11 alloy exhibits the highest TYS from all alloys. In the tensile test, the slowly extruded ME11 exhibits the lowest AE activity of all alloys. It can be explained by the strongest alignment of the basal planes (strong texture) and by the formation of the second phase particles.

In compression tests of the ME11 and MW11 alloys two peaks of the AE activity are observed, which is in 
accordance with the assumption that twins preferentially appear in large grains and only with increasing strain smaller grains also tend to twin.

The fully recrystallized and homogeneous microstructure, independently of the extrusion speed, was only observed in the MN11 alloy. This microstructure leads to high fracture strain (up to $40 \%$ ), to low yield and ultimate stresses, and to the absence of the tension-compression asymmetry.

Among $\mathrm{Ce}, \mathrm{Y}$ and $\mathrm{Nd}$ additions to $\mathrm{Mg}-\mathrm{Mn}$ extruded alloys, the addition of $\mathrm{Nd}$ decreases the average grain size most effectively and leads to the unique mechanical properties (no anisotropy).

\section{Acknowledgments}

This work received support from the Czech Science Foundation under grant P108/11/1267 and additional support was provided by the research project $1 \mathrm{M} 0556$ "Eco-centre for Applied Research of Non-ferrous Metals" financed by the Ministry of Education, Youth and Sports of the Czech Republic. K.I. is grateful for financial support from the Grant Agency of Charles University No. 166310 and also from the grant SVV-2011-263303, and F.C. is grateful to the Alexander von Humboldt Stiftung for financial support during his stay in Germany.

\section{References}

[1] Z. Keshavarz, M.R. Barnett, Scr. Mater. 55, 915 (2006).

[2] F. Hehmann, F. Sommer, B. Predel, Mater. Sci. Eng. A 125, 249 (1990).

[3] L.L. Rokhlin, Magnesium Alloys Containing Rare Earth Metals: Structure and Properties, Vol. 3, Taylor \& Francis, London 2003.

[4] Y. Chino, M. Kado, M. Mabuchi, Acta Mater. 56, 387 (2008).
[5] A.M. Becerra, M.Sc. Thesis, McGill University, Montréal, Quebec 2006.

[6] T. Uesugi, M. Kohyama, K. Higashi, Mater. Sci. Forum 419, 225 (2003).

[7] S.R. Agnew, M.H. Yoo, C.N. Tome, Acta Metall. 49, 4277 (2001)

[8] M.L. Huang, H.X. Li, H. Chen, H. Ding, S.M. Hao, J. Mater Metall. 4, 171 (2005).

[9] N. Stanford, M.R. Barnett, Scr. Mater. 59, 772 (2008).

[10] M. Masoumi, M. Hoseini, M. Pekguleryuz, Mater. Sci. Eng. A 528, 3122 (2011).

[11] J. Bohlen, S. Yi, D. Letzig, K.U. Kainer, Mater. Sci. Eng. A 527, 7098 (2010).

[12] N. Stanford, M.R. Barnett, Mater. Sci. Eng. A 496, 399 (2008).

[13] P. Dobron̆, F. Chmelík, S. Yi, K. Parfenenko, J. Bohlen, D. Letzig, Scr. Mater. 65, 424 (2011).

[14] J. Bohlen, P. Dobroň, J. Swiostek, D. Letzig, F. Chmelík, P. Lukáč, K.U. Kainer, Mater. Sci. Eng. A 462, 302 (2007).

[15] N. Stanford, M.R. Barnett, Scr. Mater. 58, 179 (2008).

[16] W. Sillekens, J. Westrum, A. Bakker, P. Vet, Mater. Sci. Forum 426, 629 (2003).

[17] K. Müller, in: Magnesium Technology, Ed. H. Kaplan, The Minerals, Metals\&Mat. Soc. TMS, Columbus, Ohio 2002 p. 187.

[18] V. Kree, J. Bohlen, D. Letzig, K.U. Kainer, Pract. Metallogr. 41, 233 (2004).

[19] Standard Practice for Acoustic Emission Examination of Fiberglass Reinforced Plastic Resin, ASTM E 1067-85, Tank/Vessels, May 31, 1985.

[20] B.H. Lee, N.S. Reddya, J.T. Yeoma, C.S. Lee, J. Mater. Process. Technol. 187-188, 766 (2007). 